Abstracta Iranica

Revue bibliographique pour le domaine irano-aryen

Volume 42-43 | 2021

Comptes rendus des publications de 2019-2020

\title{
Mohammad T. Atayi, Michael Roaf. "The arrival of the Persians into Fars"
}

\section{Rémy Boucharlat}

\section{(2) OpenEdition}

1 Journals

\section{Édition électronique}

URL : https://journals.openedition.org/abstractairanica/51697

DOI : 10.4000/abstractairanica.51697

ISSN : 1961-960X

Éditeur :

CNRS (UMR 7528 Mondes iraniens et indiens), Éditions de l'IFRI

Référence électronique

Rémy Boucharlat, " Mohammad T. Atayi, Michael Roaf. "The arrival of the Persians into Fars" », Abstracta Iranica [En ligne], Volume 42-43 | 2021, document 1, mis en ligne le 30 décembre 2020, consulté le 18 décembre 2022. URL : http://journals.openedition.org/abstractairanica/51697 ; DOI : https://doi.org/10.4000/abstractairanica.51697

Ce document a été généré automatiquement le 18 décembre 2022.

Tous droits réservés 


\section{Mohammad T. Atayi, Michael Roaf. "The arrival of the Persians into}

\section{Fars"}

Rémy Boucharlat 


\section{RÉFÉRENCE}

Mohammad T. ATAYI, Michael ROAF. "The arrival of the Persians into Fars" in Yousef Hassanzadeh, Ali A. Vahdati, Zahed Karimi (eds). Proceedings of the International Conference on The Iron Age in Western Iran and Neighbouring Regions, 2-3 Nov. 2019 Kurdistan University, Sanandaj, Iran. Vol. 2. Tehran / Sanandaj: RICHT, National Museum of Iran, Kurdistan Province ICHTO, 2019, p. 175-190.

1 Sur la question très longuement débattue de l'origine et du cheminement des Perses jusqu'à leur arrivée dans le Fars les auteurs rappellent les deux hypothèses pour eux inconciliables: l'une, qualifiée de traditionnelle, un cheminement depuis le Parsua, à situer dans le nord-ouest de l'Iran d'après les textes néo-assyriens, dans les premiers siècles du $\mathrm{I}^{\mathrm{er}}$ millénaire ; l'autre hypothèse, qualifiée de current orthodoxy, suppose une arrivée des Perses depuis leur région d'origine (non localisée) dès la fin du IIe millénaire. Pour rejeter la seconde hypothèse, les A présente une partie de la céramique du Tepe Qasr Dasht, entre Persépolis et Pasargades, site que M. T. Atayi et ses collègues iraniens ont sondé en 2016 : une rare céramique grise à rapprocher de celle de l'âge du Fer II, dans le nord-ouest de l'Iran, et des catégories de céramique du Fer III très comparables aux productions de la même région de l'ouest iranien. Ces rapprochements typologiques indiqueraient une communauté culturelle. À défaut d'être réellement convaincante, la démonstration permet de présenter du matériel totalement inédit pour une période presque inconnue dans le Fars, celle des siècles précédant l'empire achéménide.

\section{AUTEURS}

\section{RÉMY BOUCHARLAT}

UMR 5133 CNRS-Université de Lyon 